Article

\title{
Kinetics, Isotherms, and Thermodynamic Modeling of the Adsorption of Phosphates from Model Wastewater Using Recycled Brick Waste
}

\author{
Uduakobong A. Edet and Augustine O. Ifelebuegu *(1) \\ School of Energy, Construction and Environment, Coventry University, Priory Street, Coventry CV1 5FB, UK; \\ edetu@uni.coventry.ac.uk \\ * Correspondence: A.Ifelebuegu@coventry.ac.uk
}

Received: 26 April 2020; Accepted: 1 June 2020; Published: 3 June 2020

check for updates

\begin{abstract}
Phosphates in wastewater at elevated concentrations cause eutrophication of water bodies and their removal from treated wastewater is essential before effluents are discharged to the environment. Phosphates are predominately removed during wastewater treatment by chemical precipitation which is usually expensive and has a significant environmental footprint. The purpose of this study was to investigate the effectiveness of waste recycled bricks as adsorbent for phosphate removal during wastewater treatment. The kinetics, isotherms, and thermodynamics of adsorption were investigated to establish the mechanisms of adsorption. The results showed that adsorption capacities increased with an increase in contact time, adsorbent dosage, and initial phosphate concentration. The kinetic study indicated that adsorption was governed by several mechanisms with various processes dominating different stages of the adsorption. The adsorption process was better represented by the pseudo-second-order kinetics and the Langmuir isotherm adequately described the adsorption of phosphates onto brick particles with a maximum adsorption capacity of $5.35 \mathrm{mg} / \mathrm{g}$. The thermodynamic studies showed that the adsorption process was exothermic and proceeded spontaneously, demonstrating that waste bricks can be used as a sustainable alternative for the effective removal of phosphates from wastewater.
\end{abstract}

Keywords: adsorption; brick particles; phosphates; recycle; wastewater

\section{Introduction}

Eutrophication remains a major environmental pollution issue affecting $30 \%$ to $40 \%$ of lakes and reservoirs globally as estimated by the United Nations Environment Programme (UNEP) [1,2]. Phosphate is an essential macronutrient and can accumulate in environmental waters causing eutrophication through the growth and proliferation of algae and aquatic plants $[3,4]$. It is, therefore, a regulatory requirement in many countries of the world to reduce the level of phosphates in wastewater before effluents are discharged to the receiving water environment [4].

Chemical precipitation using metal salts like aluminum, calcium, and iron are the dominant methods used in the industry to remove phosphates from water to meet the stringent regulatory requirements of $0.1-2 \mathrm{mg} / \mathrm{L}[5,6]$. Adsorption using various adsorbents has been considered as a more sustainable and low-cost alternative to the use of chemical precipitation [7]. Various materials have been investigated including oyster shells [8], waste alum sludge [9], dolomite [10], and oxide tailings [11].

Clay-based materials have also been reported as having the potential to remove phosphate from wastewater. Edet et al. [12] reported on the use of fired clay pellets, Hamdi and Srasra [13] on the use of Tunisian clay minerals. Others include kaolinite [14], used bricks [15], and $\mathrm{Al}^{3+} / \mathrm{Fe}^{3+}$-modified 
bentonite [16]. Used bricks from construction waste could pose an environmental challenge in the disposal. An estimated 31.8 million tonnes per annum of demolition waste is generated in England and Scotland annually [17]. These demolition wastes have a high content of aluminum, calcium, and iron and could be applied for phosphate removal in wastewater [12]. The purpose of this study was to establish the mechanism of removal of phosphates from wastewater using recycled bricks as a sustainable alternative in wastewater treatment applications.

\section{Materials and Methods}

\subsection{Materials}

All reagents used in the study were of analytical grade and purchased from Sigma Aldrich or Fisher Scientific UK. All solutions were prepared using Reverse Osmosis (RO) purified water. Phosphate stock solutions were prepared using potassium dihydrogen phosphate $\left(\mathrm{KH}_{2} \mathrm{PO}_{4}\right)$ dissolved in $\mathrm{RO}$ water. The artificial wastewater used for the experiments was prepared as has been previously described [18]. The as-prepared wastewater was spiked with additional concentrations of phosphates to achieve the initial concentration of $20 \mathrm{mg} / \mathrm{L}$. Waste recycled bricks used during the study were sourced from southeast England. They were crushed and sieved using a $100 \mu \mathrm{m}$ mesh. The particles used were those $<100 \mu \mathrm{m}$. They were washed repeatedly with $\mathrm{RO}$ water until the electric conductivity and UV absorbance were approximately zero. The brick particles were then dried in an oven at $110^{\circ} \mathrm{C}$ to constant weight and stored in a desiccator before use.

\subsection{Characterization of Adsorbent}

The key metal oxides were analyzed using the Philips X-ray fluorescence analyzer (XRF). The brick particles were ground in a mortar and the powder was compressed into pellets using a hydraulic press. The pellets were then introduced to the sample chamber of the spectrometer with a $4 \mathrm{~kW}$ light element. The morphological features were obtained by using the scanning electron microscope model JSM-6060LV (JEOL Ltd., Tokyo, Japan).

\subsection{Batch Adsorption Experiments}

Adsorption batch experiments were conducted by using varying weights ( 1 to $5 \mathrm{~g}$ ) of brick particles in $150 \mathrm{~mL}$ of $20 \mathrm{mg} / \mathrm{L}$ phosphate solution in a capped volumetric flask placed on a temperature-controlled orbital shaker and stirred at $170 \mathrm{rpm}$. After the adsorption process, aliquots of treated wastewater $(50 \mathrm{~mL})$ were drawn at intervals and centrifuged at $5300 \mathrm{rpm}$ for $45 \mathrm{~min}$ before they were filtered using a grade 1 Whatman filter paper (11 $\mu \mathrm{m}$ pore size). Samples were then analyzed for phosphate using the molybdenum blue method with FOSS FIAstar 5000 analyzer [12]. The batch adsorption was carried out initially at varying contact times and initial phosphate concentrations ranging from $10 \mathrm{mg} / \mathrm{L}$ to $50 \mathrm{mg} / \mathrm{L}$. The adsorption capacities were determined according to the following equation:

$$
\mathrm{q}_{\mathrm{e}}=\frac{\left(\mathrm{C}_{\mathrm{o}}-\mathrm{C}_{\mathrm{t}}\right) \mathrm{V}}{\mathrm{m}}
$$

where $\mathrm{q}_{\mathrm{e}}$ is the adsorption capacity in $\mathrm{mg} / \mathrm{g}, \mathrm{C}_{\mathrm{o}}$ is the initial $\mathrm{P}$ concentration, $\mathrm{C}_{\mathrm{t}}$ is $\mathrm{P}$ concentration at time $\mathrm{t}, \mathrm{V}$ is the volume of the solution in $\mathrm{L}$, and $\mathrm{m}$ is the mass of the brick particles $(\mathrm{g})$.

The experiments for the effects of contact time were carried out at varying contact times ranging from $10 \mathrm{~min}$ to $60 \mathrm{~min}$ at an adsorbent dose of $4 \mathrm{~g}$, room temperature $\left(25^{\circ} \mathrm{C}\right)$, and $\mathrm{pH}$ of 6.7 [12]. The kinetic studies were carried out in batch conditions as above at an adsorbent dose of $4 \mathrm{~g}, 60 \mathrm{~min}$ contact time, $\mathrm{pH} 6.7$, and temperatures of $20^{\circ} \mathrm{C}, 25^{\circ} \mathrm{C}, 30^{\circ} \mathrm{C}$, and $35^{\circ} \mathrm{C}$. Isotherm and thermodynamic studies were also carried out under similar conditions. 


\section{Results and Discussion}

\subsection{Characterization of Brick Particles}

An analysis of chemical composition of the brick particles (percent $w / w$ ) showed that the approximate compositions were $\mathrm{SiO}_{2}$ (52.8\%), $\mathrm{Fe}_{2} \mathrm{O}_{3}(8.10 \%), \mathrm{Al}_{2} \mathrm{O}_{3}(16.34 \%), \mathrm{CaO}(21.14 \%), \mathrm{MgO}$ $(1.2 \%)$, and $\mathrm{MnO}(0.23 \%)$. SEM micrograph images of the brick particles before adsorption showed a surface morphology with a rough and irregular surface with visible pores measuring between 2 and $10 \mu \mathrm{m}$ in diameter. The irregular surface and presence of pores could be assumed to contribute to the total surface area, hence acting as active sites for the uptake of phosphates (Figure 1a). The surface of the brick particles used in phosphate adsorption showed the presence of prism-like crystals that are assumed to be phosphate crystallized out from the solution (Figure 1b).

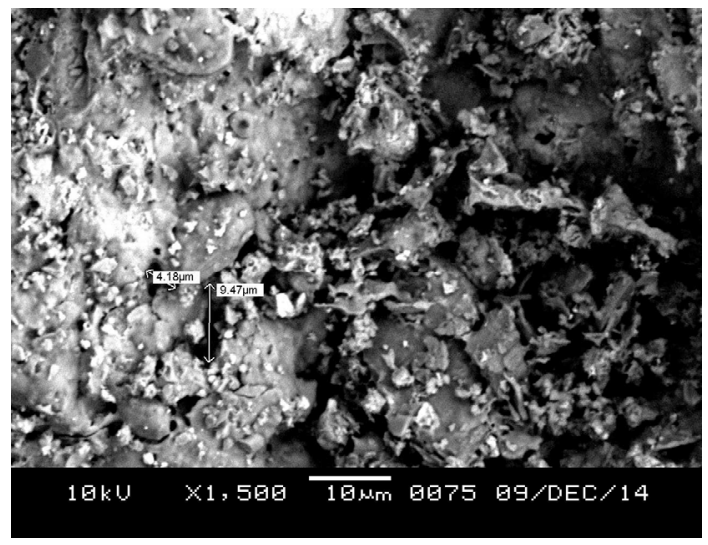

(a)

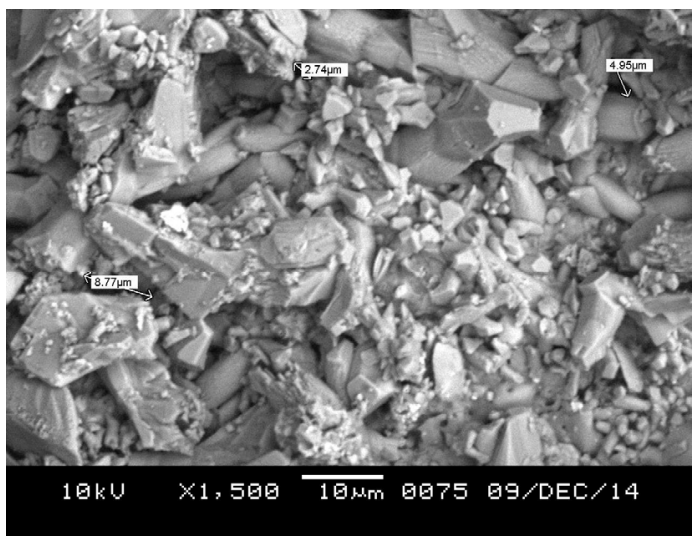

(b)

Figure 1. SEM micrograph (a) before adsorption; (b) after adsorption.

\subsection{Effect of Contact Time}

The effect of contact time on the adsorption of phosphates using brick particles was investigated by varying the adsorption time from 10 to $60 \mathrm{~min}$. The results are shown in Figure 2.

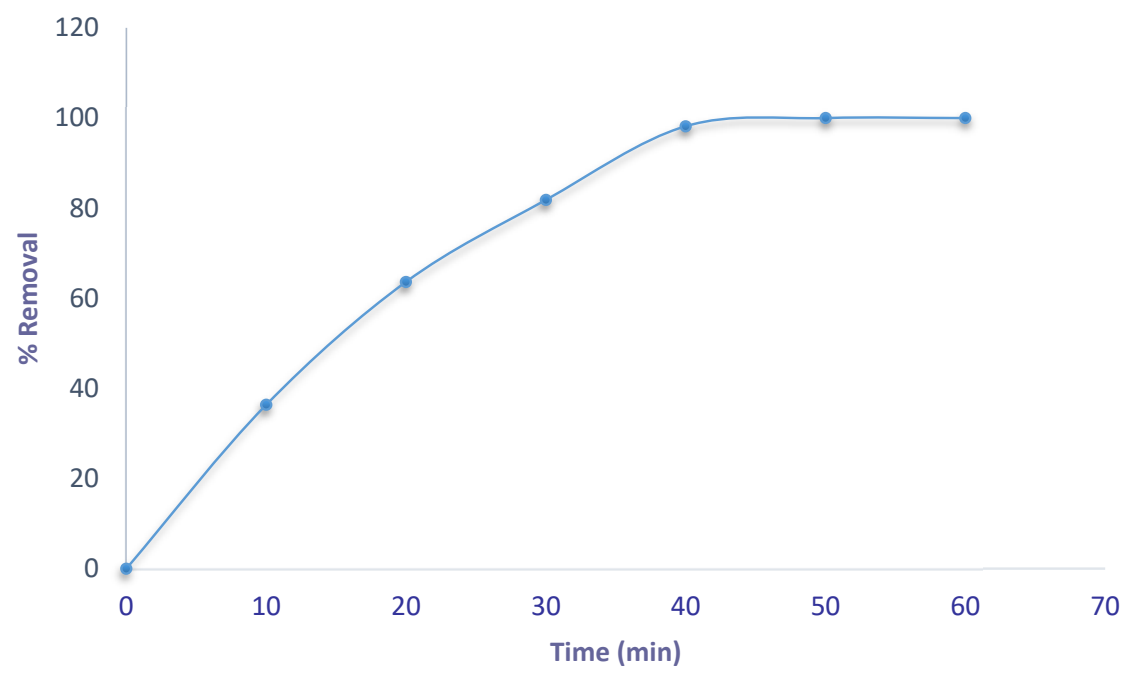

Figure 2. Effect of $\mathrm{t}$ on the sorption of phosphate onto brick particles. At $\mathrm{C}_{\mathrm{o}}=20 \mathrm{mg} / \mathrm{L}, \mathrm{pH} 6.7$, adsorbent dose $4 \mathrm{~g}$, room temperature.

As shown in the kinetic profile, there was an initial fast uptake of phosphates from wastewater in the first $10 \mathrm{~min}$ indicated by a steeper gradient before plateauing at $40 \mathrm{~min}$ of contact time. The faster 
initial uptake can be attributed to the presence of a large number of empty adsorption sites available; as the phosphate is adsorbed onto the adsorption sites of the brick particles, the number of these sites decreases, and the slope flattens as the adsorption rate decreases [19]. All subsequent experiments were conducted at $60 \mathrm{~min}$ contact time.

\subsection{Effect of Adsorbent Dosage}

The effect of the dosage of brick particles on the adsorption of phosphate from wastewater was investigated using various masses of the brick particles ( 1 to $5 \mathrm{~g}$ ).

The amount of phosphates adsorbed increased with increasing dosage of brick particles from $1.37 \mathrm{mg} / \mathrm{g}$ to $2.93 \mathrm{mg} / \mathrm{g}$ as the mass of adsorbent increased from $1 \mathrm{~g}$ to $5 \mathrm{~g}$ (Figure 3). The increased adsorbent dose resulted in an increased number of active sorption sites and surface area available for the phosphate adsorption [20,21]. The amount of phosphates adsorbed per unit mass of brick particles increased with increasing dosage before decreasing after complete adsorption of phosphates in solution due to surplus available sorption sites [22]. The decrease can also be linked with the splitting effect of the concentration gradient [22].

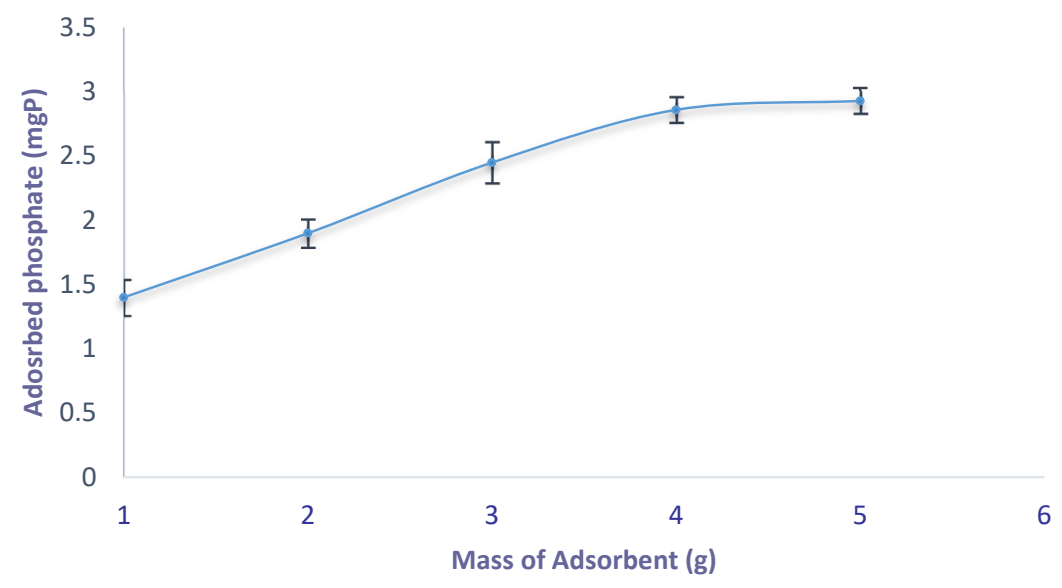

Figure 3. Effect of adsorbent mass on phosphate removal; adsorption conditions: $C_{o}=20 \mathrm{mg} / \mathrm{L}, \mathrm{pH}$ 6.7, 60 min contact time, room temperature $(n=3$, error bars represent the standard deviation of the mean of the triplicates).

\subsection{Effect of Temperature}

The effect of temperature on the adsorption process was studied at varying temperatures (20 to $\left.35^{\circ} \mathrm{C}\right)$. The result is presented in Figure 4.

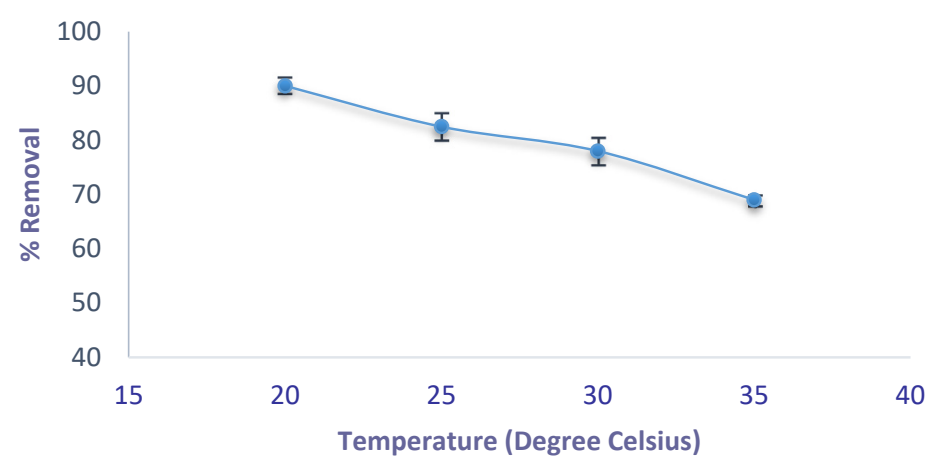

Figure 4. Effect of temperature on phosphate adsorption onto brick particles. Initial concentration $20 \mathrm{mg} / \mathrm{L}, \mathrm{pH}$ 6.7, adsorbent dose $3 \mathrm{~g}$, contact time $60 \mathrm{~min}$, room temperature ( $\mathrm{n}=3$, error bars represent the standard deviation of the mean of the triplicates). 
The adsorption of phosphate onto the brick particles decreases with an increase in temperature as shown in Figure 4. This indicates that the adsorption process is exothermic [23,24]. Phosphate ions can exhibit the inclination to migrate to the bulk solution from the solid phase as the temperature of the solution increases [10]. This, coupled with the increase in the rate of desorption of adsorbed phosphate from the adsorbent surface, could result in a decrease in the adsorption [25]. The decrease in phosphate concentrations with increasing temperature indicates a low energy requirement for the phosphate adsorption onto the brick particles. Phosphate adsorption, like most adsorption processes, is usually endothermic, but the result of this study is similar to those of Kose and Kivanc [26]. They reported a decrease in phosphate adsorption with an increase in temperature using calcined waste eggshell.

\subsection{Adsorption Kinetics Modeling}

The adsorption kinetics of phosphates onto brick particles was investigated using the pseudo-first-order, pseudo-second-order, Elovich, and Bangham's kinetic models.

The pseudo-first-order kinetic model explains the relationship between the rate the sorption sites of the adsorbents are occupied and the number of unoccupied sites. It is defined using the Lagergren equation [27] as follows:

$$
\left(\mathrm{q}_{\mathrm{e}}-\mathrm{q}_{\mathrm{t}}\right)=\ln \mathrm{q}_{\mathrm{e}}-\left(\mathrm{k}_{1} \mathrm{t}\right)
$$

where $q_{e}$ and $q_{t}$ are the amounts of phosphate adsorbed at equilibrium and at time $t$ (mins), respectively, and $\mathrm{k}_{1}$ is the rate constant of adsorption $\left(\mathrm{min}^{-1}\right)$.

The linear plot of $\ln \left(q_{e}-q_{t}\right)$ against time was used to determine the rate constant $k_{1}$.

The pseudo-second-order kinetic model describes the dependency of the adsorption capacity of the adsorbent on time and can be determined based on Equation (3) expressed as:

$$
\mathrm{t} / \mathrm{q}_{\mathrm{t}}=1 / \mathrm{k}_{2} \mathrm{qe}_{\mathrm{e}}^{2}+\mathrm{t} / \mathrm{q}_{\mathrm{e}}
$$

where $q_{t}$ and $q_{e}$ are the amounts of phosphate adsorbed at equilibrium and at time $t$ (mins), respectively, and $\mathrm{k}_{2}$ is the pseudo-second-order rate constant $(\mathrm{g} / \mathrm{mg} / \mathrm{min})$.

The linear plot of $t / q_{t}$ against time is used to determine $q_{e}$ and $k_{2}$ from the slope and intercept, respectively.

The Elovich kinetic model has been used for the chemisorption of gases onto heterogeneous surfaces and solid systems and has also now found an application for the study of the removal of pollutants from aqueous solutions [28]. It describes the second-order kinetics assuming that the solid surface has heterogeneous energy but does not propose any mechanism for adsorption [29]. The Elovich kinetic model is represented as [30]:

$$
\frac{\mathrm{dq}}{\mathrm{dt}}=\mathrm{a}^{-\alpha \mathrm{q}}
$$

where $\mathrm{q}$ is the amount of phosphate adsorbed at time $\mathrm{t}$, a is the adsorption constant, $\alpha$ is the initial rate of adsorption $(\mathrm{mg} / \mathrm{g} / \mathrm{min})$.

Integration of Equation (3) assuming the boundary conditions of $\mathrm{q}=0$ at $\mathrm{t}=0$ and $\mathrm{q}=\mathrm{q}$ at $\mathrm{t}=\mathrm{t}$ yields:

$$
\mathrm{q}=\alpha \ln (\mathrm{a} \alpha)+\alpha \ln \mathrm{t}
$$

The linear form of this equation is expressed as [31]:

$$
\mathrm{qt}=\frac{\ln \alpha \mathrm{b}}{\mathrm{b}}+\frac{1}{\mathrm{~b}} \ln \mathrm{t}
$$

where $\alpha$ is the initial rate of adsorption $(\mathrm{mg} / \mathrm{g} / \mathrm{min})$ and $\mathrm{b}$ is related to the extent of surface coverage and activation energy for chemisorption $(\mathrm{g} / \mathrm{mg})$. 
A plot of $\mathrm{q}_{\mathrm{t}}$ against $\ln \mathrm{t}$ yields a straight line with $\alpha$ and $\mathrm{b}$ determined using the slope and intercept, respectively.

Bangham's kinetic model is used to evaluate the dominance of pore diffusion in the adsorption process [32] (Subha and Namasivayam, 2008). It can be expressed as:

$$
\log \left[\frac{C_{o}}{C_{o}-q_{t} M}\right]=\log \left[\frac{k_{o}}{2.3 .3 V}\right]+\alpha \log t
$$

where $C_{o}$ is the initial concentration $(\mathrm{mg} / \mathrm{L}), \mathrm{V}$ is the volume of the solution $(\mathrm{mL}), \mathrm{M}$ is the mass of the adsorbent $(\mathrm{g} / \mathrm{L}), \mathrm{q}_{\mathrm{t}}$ is the amount of phosphate adsorbed at time $\mathrm{t}_{\mathrm{o}} \mathrm{k}_{\mathrm{o}}$ and $\alpha$ are constant.

The plot of $\log \log \left[\mathrm{C}_{\mathrm{o}} /\left(\mathrm{C}_{\mathrm{o}}-\mathrm{Mq}_{\mathrm{t}}\right)\right]$ against $\log \mathrm{t}$ yields a straight line and $\mathrm{k}_{\mathrm{o}}$ and $\alpha$ were determined from the slope and intercept, respectively.

The pseudo-first-order plot of the experimental data showed a linear relationship (Figure 5a). The rate constant $\left(\mathrm{k}_{1}\right)$ decreased initially as the temperature increased from $20^{\circ} \mathrm{C}$ to $25^{\circ} \mathrm{C}$ but showed no further change beyond $25{ }^{\circ} \mathrm{C}$ as shown in Table 1 . The equilibrium adsorption capacity $\left(\mathrm{q}_{\mathrm{e}}\right)$ calculated from the slope increased from 10.46 to $22.94 \mathrm{mg} / \mathrm{g}$ when the temperature increased from $20{ }^{\circ} \mathrm{C}$ to $25^{\circ} \mathrm{C}$ before reducing to $19.4 \mathrm{mg} / \mathrm{g}$ when the temperature increased to $35^{\circ} \mathrm{C}$. This inconsistency in the parameters of the pseudo-first-order kinetic model indicates the model does not adequately describe the adsorption process.

The pseudo-second-order kinetic model showed a better fit to the experimental data $\left(R^{2}>0.96\right)$ compared to the first-order kinetics and also had a better fit at all temperatures studied (Figure $5 \mathrm{~b}$ ). The pseudo-second-order model assumes that each phosphate ion is adsorbed onto two adsorption sites which allows a stable binuclear bond to form. The rate constant $\left(\mathrm{k}_{2}\right)$ and the initial rate of reaction (h) decreased with increasing temperature. The rate constant decreased from 0.06 to $0.03 \mathrm{~g} / \mathrm{mg} / \mathrm{min}$ while the initial rate of reaction decreased from 0.04 to $0.02 \mathrm{mg} / \mathrm{g} / \mathrm{min}$ as temperature increased from $20{ }^{\circ} \mathrm{C}$ to $35^{\circ} \mathrm{C}$. This decrease in the second-order rate constant with increasing temperature could be attributed to the propensity of adsorbate to migrate from the solid phase to the bulk phase with increasing temperature of the wastewater [10,33]. A similar result has been reported by Karaca et al. [10] using dolomite for the adsorptive removal of phosphate from the solution.

The Elovich equation could also be used to describe phosphate adsorption onto brick particles. The plot of $\mathrm{q}_{\mathrm{t}}$ against $\ln \mathrm{t}$ showed a good fit to the experimental data (Figure $5 \mathrm{c}$ ). The values of the initial adsorption rate $(\alpha)$ and desorption constant $(b)$ varied as a function of temperature. The initial adsorption rate increased from 0.82 to $0.86 \mathrm{mg} / \mathrm{g} / \mathrm{min}$ as the temperature increased from $20^{\circ} \mathrm{C}$ to $25^{\circ} \mathrm{C}$ before declining to $0.76 \mathrm{mg} / \mathrm{g} / \mathrm{min}$ as the temperature increased to $35{ }^{\circ} \mathrm{C}$ (Table 1). The desorption constant fluctuated with temperature with $b$ increasing from 5.1 to $5.9 \mathrm{~g} / \mathrm{mg}$ when the temperature increased from $20^{\circ} \mathrm{C}$ to $25^{\circ} \mathrm{C}$ before reducing to $5.38 \mathrm{~g} / \mathrm{mg}$ at $30^{\circ} \mathrm{C}$ and increasing slightly to $5.46 \mathrm{~g} / \mathrm{mg}$ at $35^{\circ} \mathrm{C}$. Overall, the desorption rate was lowest at $20^{\circ} \mathrm{C}$ and could explain the higher adsorption at $20^{\circ} \mathrm{C}$ reported in the previous section.

Bangham's kinetic model showed a good fit to the experimental data with $R^{2}$ values $>0.95$ for all temperatures studied (Figure 5d). The kinetic plots showed the best bit of all the kinetic models investigated. Bangham's constants $\mathrm{k}_{\mathrm{o}}$ and $\alpha$ fluctuated with variation in temperature. The value of $\mathrm{k}_{\mathrm{o}}$ decreased from 44 to $39.35 \mathrm{~mL} / \mathrm{g} / \mathrm{L}$ when the temperature increased from $20{ }^{\circ} \mathrm{C}$ to $25^{\circ} \mathrm{C}$ before increasing to $51.2 \mathrm{~mL} / \mathrm{g} / \mathrm{L}$ and $61.84 \mathrm{~mL} / \mathrm{g} / \mathrm{L}$ as the temperature increased to $30^{\circ} \mathrm{C}$ and $35^{\circ} \mathrm{C}$, respectively. $\alpha$ increased from $9.5 \times 10^{-3}$ to $9.9 \times 10^{-3}$ when the temperature increased from $20^{\circ} \mathrm{C}$ to $25^{\circ} \mathrm{C}$ before reducing to $6.07 \times 10^{-3}$ and $4.07 \times 10^{-3}$ as the temperature increased to $30^{\circ} \mathrm{C}$ and $35^{\circ} \mathrm{C}$, respectively. The fluctuation in the parameters does not show a trend that could be derived as the function of temperature. The high $R^{2}$ values show some degree of pore diffusion but it was not a rate-limiting step in the adsorption process. 

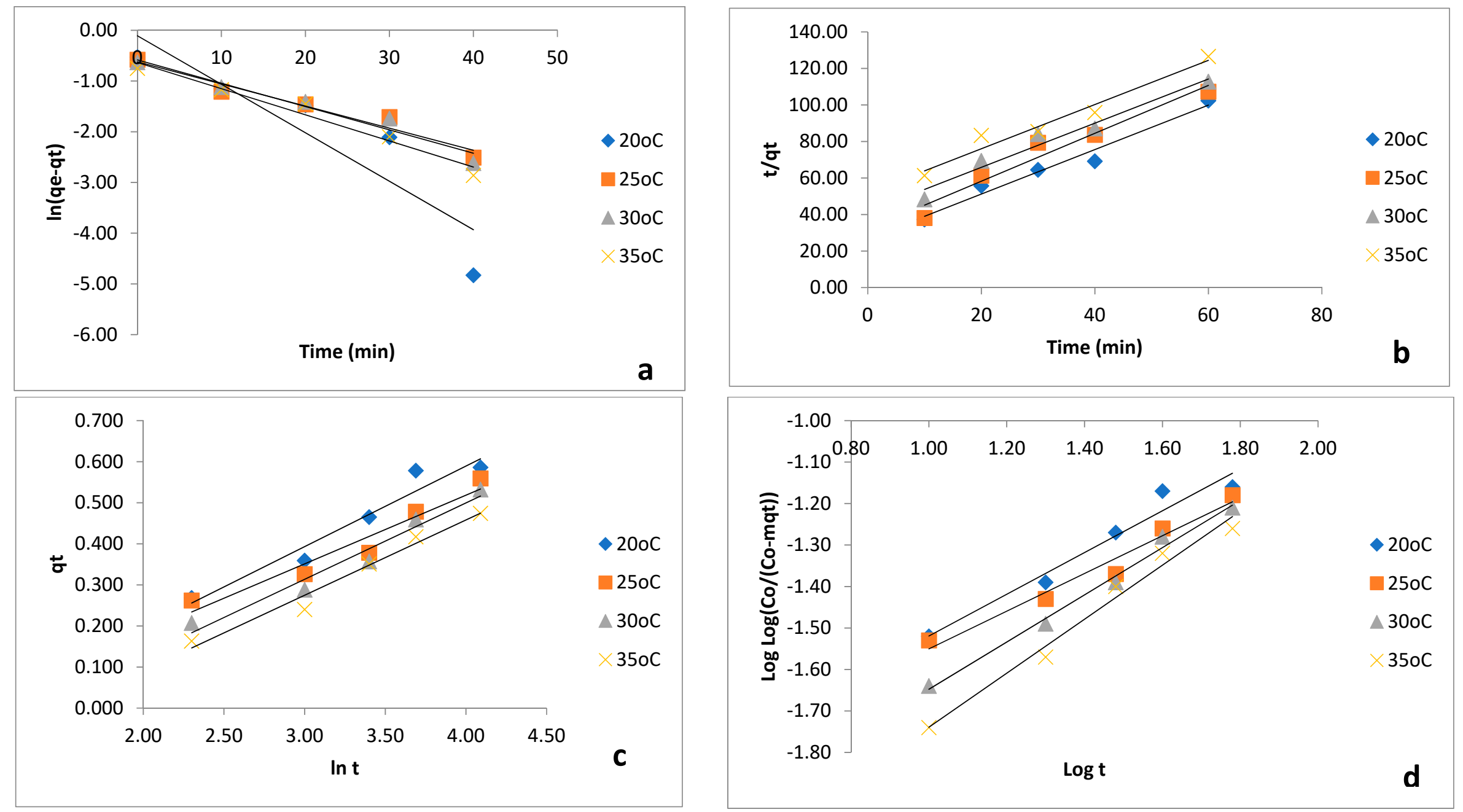

Figure 5. Kinetic model plots for phosphate adsorption onto adsorbent particles $\left(\mathrm{C}_{\mathrm{o}}=20 \mathrm{mg} / \mathrm{L}, \mathrm{pH} 6.7\right.$, adsorbent dose $4 \mathrm{~g}, \mathrm{t}=60$ min): (a) pseudo-first-order kinetic model; (b) pseudo-second-order kinetic model; (c) Elovich kinetic model; and (d) Bangham's kinetic model. 
Table 1. Parameters for various kinetic models: initial concentration $20 \mathrm{mg} / \mathrm{L}, \mathrm{pH} 6.7$, adsorbent dose $4 \mathrm{~g}, \mathrm{t}=60 \mathrm{~min}$.

\begin{tabular}{|c|c|c|c|c|c|}
\hline Kinetic Model & Parameter & $20^{\circ} \mathrm{C}$ & $25^{\circ} \mathrm{C}$ & $30^{\circ} \mathrm{C}$ & $35^{\circ} \mathrm{C}$ \\
\hline \multirow{3}{*}{ Pseudo-first-order } & $\mathbf{k}_{1}(/ \min )$ & -0.05 & -0.03 & -0.03 & -0.03 \\
\hline & $\mathrm{q}_{\mathrm{e}}(\mathrm{mg} / \mathrm{g})$ & 10.46 & 22.94 & 21.74 & 19.42 \\
\hline & $\mathbf{R}^{2}$ & 0.818 & 0.9523 & 0.9526 & 0.966 \\
\hline \multirow{3}{*}{ Pseudo-second-order } & $\begin{array}{c}\mathrm{k}_{2} \\
(\mathrm{~g} / \mathrm{mg} / \mathrm{min})\end{array}$ & 0.06 & 0.05 & 0.04 & 0.03 \\
\hline & h (mg/g/min) & 0.04 & 0.04 & 0.02 & 0.02 \\
\hline & $\mathbf{R}^{2}$ & 0.9686 & 0.9498 & 0.9601 & 0.96 \\
\hline \multirow{3}{*}{ Elovich } & $\alpha(\mathrm{mg} / \mathrm{g} / \mathrm{min})$ & 0.82 & 0.86 & 0.78 & 0.76 \\
\hline & $b(\mathrm{~g} / \mathrm{mg})$ & 5.1 & 5.97 & 5.38 & 5.46 \\
\hline & $\mathbf{R}^{2}$ & 0.9445 & 0.9326 & 0.9599 & 0.9731 \\
\hline \multirow{3}{*}{ Bangham's } & $k_{o}(\mathrm{~mL} / \mathrm{g} / \mathrm{L}$ & 44 & 39.35 & 51.20 & 61.84 \\
\hline & $\alpha$ & $9.50 \times 10^{-3}$ & $9.90 \times 10^{-3}$ & $6.07 \times 10^{-3}$ & $4.07 \times 10^{-3}$ \\
\hline & $\mathbf{R}^{2}$ & 0.9587 & 0.965 & 0.9897 & 0.9803 \\
\hline
\end{tabular}

\subsection{Adsorption Isotherm}

The adsorption isotherm for the adsorptive removal of phosphate by brick particles was investigated using the Langmuir, Freundlich, Temkin, and Dubinin-Radushkevich isotherm models.

\subsubsection{Langmuir Isotherm}

The Langmuir model describes monolayer sorption on distinct localized adsorption sites. It indicates no transmigration of the adsorbate in the plane of the surfaces and assumes uniform energies of monolayer sorption onto the sorbent surface [34]. The linearized form of the Langmuir isotherm is expressed as:

$$
\frac{\mathrm{C}_{\mathrm{e}}}{\mathrm{C}_{\mathrm{ads}}}=\frac{1}{\mathrm{Q}_{\mathrm{b}}}+\frac{\mathrm{C}_{\mathrm{e}}}{\mathrm{Q}}
$$

where $C_{e}$ is the equilibrium concentration of phosphate $(\mathrm{mg} / \mathrm{L}), \mathrm{C}_{\mathrm{ads}}$ is the amount of phosphate sorbed at equilibrium, $b$ is the sorption constant $(\mathrm{L} / \mathrm{mg})$ at a given temperature, related to the energy of sorption, $\mathrm{Q}$ is the maximum sorption capacity $(\mathrm{mg} / \mathrm{g})$.

The Langmuir isotherm model can also be expressed as [35]:

$$
\mathrm{q}_{\mathrm{e}}=\frac{\mathrm{Q}_{\mathrm{m}} \mathrm{K}_{\mathrm{L}} \mathrm{C}_{\mathrm{e}}}{1+\mathrm{K}_{\mathrm{L}} \mathrm{C}_{\mathrm{e}}}
$$

where $C_{e}$ is the equilibrium constant $(\mathrm{mg} / \mathrm{L}), \mathrm{q}_{\mathrm{e}}$ is the amount of phosphate adsorbed equilibrium $(\mathrm{mg} / \mathrm{g}), \mathrm{Q}_{\mathrm{m}}$ is the maximum monolayer coverage capacity $(\mathrm{mg} / \mathrm{g}), \mathrm{K}_{\mathrm{L}}$ is the Langmuir isotherm constant (L/mg).

A dimensionless constant or separation factor $\left(R_{L}\right)$ is represented as [36]:

$$
\mathrm{R}_{\mathrm{L}}=\frac{1}{1+\mathrm{K}_{\mathrm{L}} \mathrm{C}_{\mathrm{o}}}
$$

$R_{L}$ is used to describe the favorable nature of the adsorption process where $R_{L}>1$ is unfavorable, $\mathrm{R}_{\mathrm{L}}=0$ is linear, $0<\mathrm{R}_{\mathrm{L}}<1$ is favorable, and $\mathrm{R}_{\mathrm{L}}=0$ is irreversible [28,36] (Foo and Hameed 2010; Yuan et al. 2015). A plot of $1 / q_{e}$ against $1 / C_{e}$ yielded a straight line graph with the values of $Q_{m}$ and $K_{L}$ calculated from the slope and intercept, respectively. 


\subsubsection{Freundlich Isotherm}

The Freundlich isotherm is used to describe adsorption processes that occur on heterogeneous surfaces and active sites with different energies based on multilayer adsorption and equilibrium [34,37]. The linear form of the Freundlich isotherm model is represented as follows [35,38]:

$$
\ln Q=\ln K_{f}+\frac{1}{n} \ln C_{e}
$$

The isotherm is expressed as:

$$
\mathrm{Q}_{\mathrm{e}}=\mathrm{K}_{\mathrm{f}} \mathrm{C}^{1 / \mathrm{n}} \quad \mathrm{n}>1
$$

where $\mathrm{K}_{\mathrm{f}}$ is the Freundlich isotherm constant, $\mathrm{n}$ is adsorption intensity, $\mathrm{C}_{\mathrm{e}}$ is the equilibrium concentration of adsorbate $(\mathrm{mg} / \mathrm{L}), Q_{\mathrm{e}}$ is the amount of phosphate adsorbed at equilibrium $(\mathrm{mg} / \mathrm{g})$.

The linear form of Equation (12) is expressed as:

$$
\log Q_{e}=\log K_{f}+\frac{1}{n} \log C_{e}
$$

The plot of $\log q_{e}$ against $\log C_{e}$ yielded a straight line and $n$ and $K_{f}$ were calculated from the slope and intercept, respectively.

$\mathrm{K}_{\mathrm{f}}$ and $\mathrm{n}$ are Freundlich constants and represent the adsorption capacity and adsorption intensity, respectively. $K_{f}$ and $n$ are derived from the intercept and slope, respectively, of a graph of $\ln Q$ against $\ln \mathrm{C}_{\mathrm{e}}$.

$\mathrm{Q}$ is the sorbed phosphate and $\mathrm{C}_{\mathrm{e}}$ is the equilibrium concentration of phosphate in the solution.

\subsubsection{Tempkin Adsorption Isotherm}

The Tempkin adsorption isotherm contains a factor that considers the interaction between adsorbates [35]. The model assumes that the heat of adsorption of all molecules in the layer will decrease linearly rather than logarithmically with coverage at average concentrations [35,36,39]. The heat of adsorption is characterized by a uniform distribution of binding energies up to some maximum binding energy [36]. The model is expressed as:

$$
\begin{gathered}
\mathrm{q}_{\mathrm{e}}=\frac{\mathrm{R}_{\mathrm{T}}}{\mathrm{b}} \ln \left(\mathrm{A}_{\mathrm{T}} \mathrm{C}_{\mathrm{e}}\right) \\
\mathrm{qe}=\frac{\mathrm{R}_{\mathrm{T}}}{\mathrm{b}_{\mathrm{T}}} \ln \mathrm{A}_{\mathrm{T}}+\left[\frac{\mathrm{R}_{\mathrm{T}}}{\mathrm{b}}\right] \ln \mathrm{C}_{\mathrm{e}} \\
\mathrm{B}=\frac{\mathrm{R}_{\mathrm{T}}}{\mathrm{b}_{\mathrm{T}}} \\
\mathrm{qe}=\mathrm{B} \ln \mathrm{A}_{\mathrm{T}}+\mathrm{B} \ln \mathrm{C}_{\mathrm{e}}
\end{gathered}
$$

where $A_{T}$ is the Tempkin isotherm equilibrium binding constant $(\mathrm{L} / \mathrm{g}), \mathrm{B}_{\mathrm{T}}$ is the Tempkin isotherm constant, $R$ is the universal gas constant $(8.314 \mathrm{~J} / \mathrm{mol} / \mathrm{K}), \mathrm{T}$ is temperature at $298 \mathrm{~K}$, and $\mathrm{B}$ is the constant related to heat of sorption $(\mathrm{J} / \mathrm{mol}) . \mathrm{A}_{\mathrm{T}}$ and $\mathrm{b}_{\mathrm{T}}$ were determined from the intercept and slope, respectively, of the plot of qt against $\ln \mathrm{t}$.

\subsubsection{Dubinin-Radushkevich Adsorption Isotherm}

The Dubinin-Radushkevich adsorption isotherm is used to describe the adsorption mechanism with a Gaussian energy distribution on a heterogeneous surface [35,40]. The Dubinin-Radushkevich adsorption isotherm does not assume homogeneous surface or constant sorption potential and helps to determine the apparent energy of adsorption [41]. The model is expressed as:

$$
\ln \mathrm{q}_{\mathrm{e}}=\ln \mathrm{q}_{\mathrm{s}}-\beta \varepsilon^{2}
$$


where $\mathrm{q}_{\mathrm{e}}$ is the amount of phosphate adsorbed at equilibrium $(\mathrm{mg} / \mathrm{g}), \mathrm{q}_{\mathrm{m}}$ is the theoretical isotherm saturation capacity $(\mathrm{mg} / \mathrm{g}), \beta$ is the Dubinin-Radushkevich isotherm constant $\left(\mathrm{mol}^{2} / \mathrm{kJ}^{2}\right), \varepsilon$ is the Polanyi potential, which is equal to

$$
\varepsilon=\mathrm{RT} \ln \left(1+\frac{1}{\mathrm{C}_{\mathrm{e}}}\right)
$$

Where $\mathrm{R}$ is the universal gas constant $(8.314 \mathrm{~J} / \mathrm{mol} / \mathrm{K})$.

The model is used to distinguish the physical and chemical adsorption with its mean free energy, $\mathrm{E}(\mathrm{kJ} / \mathrm{mol})$, required to remove a molecule of adsorbate from its location in the sorption site to infinity. E is computed using Equation (20):

$$
\mathrm{E}=\left[\frac{1}{\sqrt{ } 2 \beta}\right]
$$

The Langmuir isotherm showed the better fit of all isotherm models studied except the Tempkin isotherm. Maximum adsorption capacity of $Q_{m}=5.35 \mathrm{mg} / \mathrm{g}$ was derived from the evaluation of the Langmuir isotherm plot (Figure 6a). The Langmuir isotherm constant $\left(\mathrm{K}_{\mathrm{L}}\right)$ and $\mathrm{R}_{\mathrm{L}}$ were determined as $0.25 \mathrm{~L} / \mathrm{mg}$ and 0.04 , respectively (Table 2 ). The $\mathrm{R}_{\mathrm{L}}$ value was less than 1 , indicating that the adsorption of phosphate onto the surface of the brick particles was a favorable process. It also describes monolayer sorption where each phosphate molecule is adsorbed on distinct localized sorption sites with no transmigration of the adsorbate in the plane of the surfaces giving uniform energies of monolayer sorption onto the adsorbent surface [34]. The good fit of the experimental data to the Langmuir isotherm indicates a more physical sorption mechanism (physisorption). The value of the maximum adsorption capacity obtained for brick particles was similar to the values obtained by [16] using $\mathrm{Al}^{3+}$-modified bentonite for the removal of phosphates.
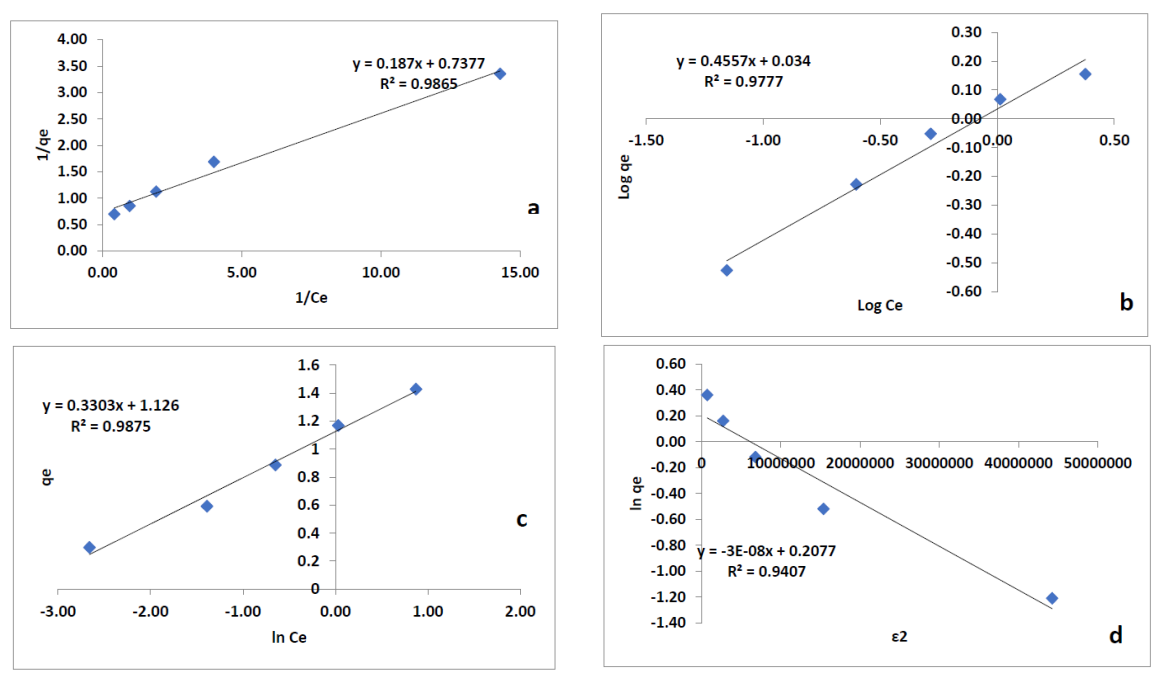

Figure 6. Adsorption isotherm plots (initial concentration $20 \mathrm{mg} / \mathrm{L}, \mathrm{pH} \mathrm{6.7,} \mathrm{adsorbent} \mathrm{dose} 4 \mathrm{~g}$, $\mathrm{t}=60 \mathrm{~min}$ ): (a) Langmuir adsorption isotherm; (b) Freundlich adsorption isotherm; (c) Tempkin adsorption isotherm; and (d) Dubinin-Radushkevich adsorption isotherm. 
Table 2. Adsorption isotherm parameters for the adsorption of phosphate onto brick particles.

\begin{tabular}{|c|c|c|}
\hline Adsorption Isotherm Model & Parameter & Brick Particles \\
\hline \multirow{4}{*}{ Langmuir Isotherm } & $Q_{m}(m g / g)$ & 5.35 \\
\hline & $\mathrm{K}_{\mathrm{L}}(\mathrm{L} / \mathrm{mg})$ & 0.25 \\
\hline & $\mathbf{R}_{\mathbf{L}}$ & 0.04 \\
\hline & $\mathbf{R}^{2}$ & 0.9865 \\
\hline \multirow{4}{*}{ Freundlich Isotherm } & $k_{\mathrm{f}}(\mathrm{mg} / \mathrm{g})$ & 1.08 \\
\hline & $\frac{1}{n}$ & 0.4557 \\
\hline & $\mathbf{n}$ & 2.19 \\
\hline & $\mathbf{R}^{2}$ & 0.9777 \\
\hline \multirow{4}{*}{ Temkin Isotherm } & $A_{T}(L / m g)$ & 1.19 \\
\hline & $\mathbf{b}$ & 1287.51 \\
\hline & $B(\mathrm{~J} / \mathrm{mol})$ & 1.89 \\
\hline & $\mathbf{R}^{2}$ & 0.9897 \\
\hline \multirow{3}{*}{$\begin{array}{l}\text { Dubinin-Radushkevich } \\
\text { Isotherm }\end{array}$} & $\mathrm{B}\left(\mathrm{mol}^{2} / \mathrm{kJ}^{2}\right)$ & $2.84 \times 10^{-7}$ \\
\hline & $\mathrm{E}(\mathrm{kJ} / \mathrm{mol})$ & 1.35 \\
\hline & $\mathrm{R}^{2}$ & 0.9351 \\
\hline
\end{tabular}

For the Dubinin-Radushkevich (D-R) isotherm model, the $\mathrm{R}^{2}$ value of (0.9351) was lower than both the Langmuir and Tempkin isotherms (Figure $6 \mathrm{~d}$ ). The value of $\mathrm{E}$ is used in the prediction of the type of adsorption; E values $<8 \mathrm{~kJ} / \mathrm{mol}$ are usually classified as proceeding by physisorption. A value of $1.35 \mathrm{~kJ} / \mathrm{mol}$ was obtained for the adsorption of phosphates onto brick particles supporting the earlier proposed dominant mechanism of physisorption.

The results of the Freundlich isotherm model showed a good fit to the experimental data $\left(\mathrm{R}^{2}=0.9777\right)$ (Figure $\left.6 \mathrm{~b}\right)$. Adsorption intensity $\mathrm{n}$ is used to describe the heterogeneity of the adsorption surface; a smaller $1 / \mathrm{n}$ value indicates a more heterogeneous surface and an $\mathrm{n}$ value between 1 and 10 indicates a favorable process. The values of 0.46 and 2.19 were respectively obtained for $1 / n$ and $n$ (Table 2), indicating that the adsorption of phosphate to brick particles was favorable and happened on heterogeneous surfaces.

The Tempkin isotherm determines the heat of sorption which could be used to describe the adsorption process. The Tempkin isotherm showed a good fit with the experimental data for all isotherms studied (Figure $6 \mathrm{c}$ ). $\mathrm{A}_{\mathrm{T}}$ and $B$ values were $1.19 \mathrm{~L} / \mathrm{mg}$ and $1.89 \mathrm{~J} / \mathrm{mol}$, respectively (Table 2). The positive value of $B$ means the adsorption was exothermic, confirming the result of the kinetic study.

\subsection{Thermodynamic of Adsorption}

The thermodynamic parameters of Gibbs free energy $\left(\Delta \mathrm{G}^{\circ}\right)$, enthalpy $\left(\Delta \mathrm{H}^{\circ}\right)$, and entropy $\left(\Delta \mathrm{S}^{\circ}\right)$ are used in the determination of spontaneity of the adsorption process, the nature of the adsorption process, and also the adsorbent applicability [42]. The parameters $\Delta \mathrm{G}, \Delta \mathrm{S}$, and $\Delta \mathrm{H}$ were evaluated using the expressions in Equations (21) and (22).

$$
\Delta \mathrm{G}=\Delta \mathrm{H}^{\mathrm{o}}-\Delta \mathrm{S}^{\mathrm{o}}
$$

where $\mathrm{T}$ is the temperature in Kelvin and $\Delta \mathrm{H}$ and $\Delta \mathrm{S}$ correspond to the slope and intercept, respectively, of a graph of $\ln \mathrm{K}_{\mathrm{d}}$ against $1 / \mathrm{K}$. 
The activation energy $E_{a}$ was derived from the Arrhenius equation:

$$
\ln K d=\ln \mathrm{A}-\frac{\mathrm{E}_{\mathrm{a}}}{\mathrm{R}_{\mathrm{T}}}
$$

where $K_{d}$ is the rate constant, $A$ is the Arrhenius constant $(\mathrm{J} / \mathrm{mol} / \mathrm{K}), \mathrm{E}_{\mathrm{a}}$ is the activation energy $(\mathrm{KJ} / \mathrm{mol})$, $\mathrm{R}$ is the universal constant $(\mathrm{J} / \mathrm{molK}), \mathrm{T}$ is temperature in $\mathrm{K}$. $\mathrm{E}_{\mathrm{a}}$ was obtained from the slope of plotting $K_{d}$ against $1 / T$.

A plot of $\ln K_{d}$ against $1 / T$, as illustrated in Figure 7, gave a linear relationship with $\Delta \mathrm{H}^{\circ}$ and $\Delta \mathrm{S}^{\circ}$ evaluated from the slope and intercept, respectively, of the van't Hoff plot and $\Delta \mathrm{G}$ was calculated using Equation (8) $[43,44]$. The thermodynamic parameters for the phosphate adsorption onto brick particles are shown in Table 3.

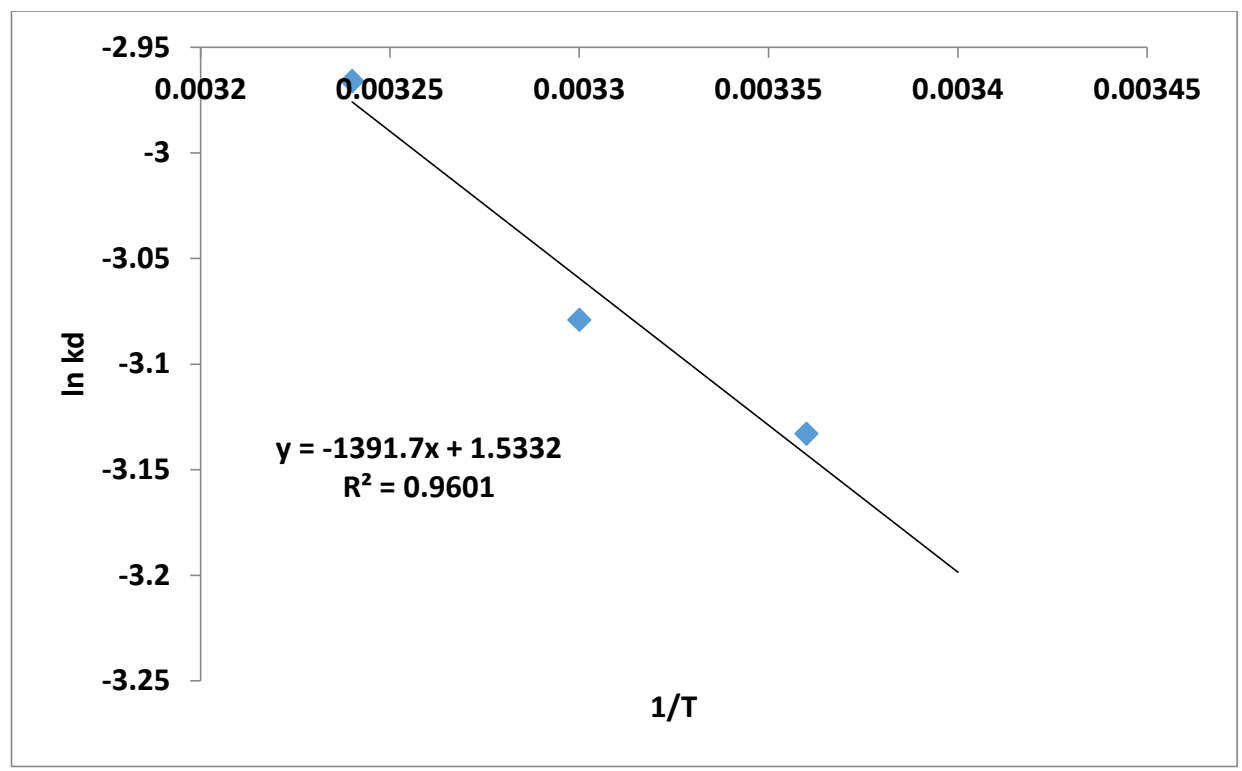

Figure 7. Van't Hoff plot for the adsorption of phosphate using brick particles.

Table 3. Thermodynamic parameters for the adsorption of phosphate by brick dust.

\begin{tabular}{cc}
\hline Parameter & Brick Particles \\
\hline$\Delta \mathrm{G}^{\mathrm{o}}$ & -0.595 \\
\hline$\Delta \mathrm{H}^{\mathrm{o}}(\mathrm{KJ} / \mathrm{mol})$ & -0.139 \\
\hline$\Delta \mathrm{S}^{\mathrm{o}}(\mathrm{KJ} / \mathrm{mol} / \mathrm{K})$ & $1.53 \times 10^{-3}$ \\
\hline $\mathrm{E}_{\mathrm{a}}(\mathrm{J} / \mathrm{mol})$ & 0.012 \\
\hline $\mathrm{A}$ & 0.572 \\
\hline
\end{tabular}

A negative value was obtained for $\Delta G^{o}$ at all temperatures studied (Table 3). This confirms the spontaneous nature of the adsorption process. The results are similar to those obtained by the use of mixed lanthanum/aluminum pillared montmorillonite for the adsorption of phosphate [23]. The values of $\Delta \mathrm{G}^{\circ}$ suggest a physisorption process as values of $\Delta \mathrm{G}^{\circ}$ for the physisorption process are generally between $-20 \mathrm{KJ} / \mathrm{mol}$ and $0 \mathrm{KJ} / \mathrm{mol}$. The negative value of $\Delta \mathrm{H}^{\circ}(-0.139 \mathrm{KJ})$ confirmed the exothermic nature of the process. The positive value of $\Delta \mathrm{S}^{\circ}\left(1.53 \times 10^{-3} \mathrm{KJ} / \mathrm{mol} / \mathrm{K}\right)$ indicated the increased randomness at the solid-solution interface during the adsorption process and a good affinity of phosphate ions towards brick particles [42]. The value of the activation energy $E_{a}(0.012 \mathrm{~J} / \mathrm{mol})$ indicated a relatively low energy barrier and confirmed the exothermic nature of the adsorption process. 
The overall results demonstrate the potential application of recycled bricks as a sustainable adsorbent for the removal of phosphate in a filter bed, post biological treatment.

\section{Conclusions}

This study demonstrated the applicability of waste recycled bricks as a sustainable adsorbent for the removal of phosphates from wastewater. The results of the batch experiments indicated that the adsorption process was affected by adsorbent dose, contact time, initial phosphate concentration, and temperature. The kinetic study indicated adsorption was governed by several mechanisms with various processes dominating different stages of adsorption. Isotherm studies showed the adsorption could be described by Langmuir, Freundlich, Tempkin, and Dubinin-Radushkevich isotherms with a maximum adsorption capacity of $5.35 \mathrm{mg} / \mathrm{g}$. The thermodynamic investigation showed that removal of phosphates by brick particles was feasible, exothermic, and spontaneous in nature.

Author Contributions: Conceptualization, U.A.E. and A.O.I.; methodology, U.A.E. and A.O.I.; formal analysis, U.A.E.; investigation, U.A.E.; resources, A.O.I.; data curation, U.A.E. and A.O.I.; writing-original draft preparation, U.A.E.; writing-review and editing, A.O.I.; supervision, A.O.I. All authors have read and agreed to the published version of the manuscript.

Funding: This research received financial support toward tuition from the Niger Delta Development Commission.

Acknowledgments: The authors acknowledge the funding received from the Niger Delta Development Commission, Nigeria.

Conflicts of Interest: The authors declare no conflict of interest.

\section{References}

1. Le Moal, M.; Gascuel-Odoux, C.; Ménesguen, A.; Souchon, Y.; Étrillard, C.; Levain, A.; Moatar, F.; Pannard, A.; Souchu, P.; Lefebvre, A.; et al. Eutrophication: A new wine in an old bottle? Sci. Total Environ. 2019, 651, 1-11. [CrossRef] [PubMed]

2. Pawar, R.R.; Gupta, P.; Bajaj, L.H.; Lee, S.-M. Al-intercalated acid activated bentonite beads for the removal of aqueous phosphate. Sci. Total Environ. 2016, 572, 1222-1230. [CrossRef]

3. Yoon, S.-Y.; Lee, C.-G.; Park, J.-A.; Kim, J.-H.; Kim, S.-B.; Lee, S.-H.; Choi, J.-W. Kinetic, equilibrium and thermodynamic studies for phosphate adsorption to magnetic iron oxide nanoparticles. Chem. Eng. J. 2014, 236, 341-347. [CrossRef]

4. Ifelebuegu, A.O.; Ojo, P. Modelling the effects of ferric salt dosing for chemical phosphorus removal on the settleability of activated sludge. J. Environ. Chem. Eng. 2019, 7, 103256. [CrossRef]

5. Xie, J.; Lin, Y.; Li, C.; Wu, D.; Kong, H. Removal and recovery of phosphate from water by activated aluminum oxide and lanthanum oxide. Powder Technol. 2015, 269, 351-357. [CrossRef]

6. Ojo, P.; Ifelebuegu, A. The Impact of Aluminium Salt Dosing for Chemical Phosphorus Removal on the Settleability of Activated Sludge. Environments 2018, 5, 88. [CrossRef]

7. Yan, Y.; Sun, X.; Ma, F.; Li, J.; Shen, J.; Han, W.; Liu, X.; Wang, L. Removal of phosphate from etching wastewater by calcined alkaline residue: Batch and column studies. J. Taiwan Inst. Chem. Eng. 2014, 45, 1709-1716. [CrossRef]

8. Chen, W.-T.; Lin, C.-W.; Shih, P.-K.; Chang, W.-L. Adsorption of phosphate into waste oyster shell: Thermodynamic parameters and reaction kinetics. Desalin. Water Treat. 2012, 47, 86-95. [CrossRef]

9. Babatunde, A.; Zhao, Y. Equilibrium and kinetic analysis of phosphorus adsorption from aqueous solution using waste alum sludge. J. Hazard. Mater. 2010, 184, 746-752. [CrossRef]

10. Karaca, S.; Gurses, A.; Ejder, M.; Açıkyıldız, M. Kinetic modeling of liquid-phase adsorption of phosphate on dolomite. J. Colloid Interface Sci. 2004, 277, 257-263. [CrossRef]

11. Zeng, L.; Li, X.; Liu, J. Adsorptive removal of phosphate from aqueous solutions using iron oxide tailings. Water Res. 2004, 38, 1318-1326. [CrossRef] [PubMed]

12. Edet, U.A.; Ifelebuegu, A.; Wood, A.; Bateman, M. The Adsorptive Properties of Fired Clay Pellets for the Removal of Phosphate in Wastewater Treatment. In Proceedings of the Fourth International Conference on Advances in Bio-Informatics, Bio-Technology and Environmental Engineering (ABBE 2016), Birmingham, UK, 17-18 March 2016; pp. 15-21. 
13. Hamdi, N.; Srasra, E. Removal of phosphate ions from aqueous solution using Tunisian clays minerals and synthetic zeolite. J. Environ. Sci. 2012, 24, 617-623. [CrossRef]

14. Kamiyango, M.; Masamba, W.R.L.; Sajidu, S.; Fabiano, E. Phosphate removal from aqueous solutions using kaolinite obtained from Linthipe, Malawi. Phys. Chem. Earth Parts A/B/C 2009, 34, 850-856. [CrossRef]

15. Jia, C.; Dai, Y.; Chang, J.-J.; Wu, C.; Wu, Z.-B.; Liang, W. Adsorption characteristics of used brick for phosphorus removal from phosphate solution. Desalin. Water Treat. 2013, 51, 5886-5891. [CrossRef]

16. Shanableh, A.; Enshasi, G.; Elsergany, M. Phosphorous Adsorption using $\mathrm{Al}^{3+} / \mathrm{Fe}^{3+}-\mathrm{Modified} \mathrm{Bentonite}^{3}$ adsorbents-Effect of $\mathrm{Al}^{3+}$ and $\mathrm{Fe}^{3+}$ Combinations. Desalin. Water Treat. 2016, 57, 15628-15634. [CrossRef]

17. CRWP. Overview of Demolition Waste in the UK. 2009. Available online: http://www.wrap.org.uk/sites/files/ wrap/CRWP-Demolition-Report-2009.pdf (accessed on 16 June 2019).

18. Zhu, L.; Hiltunen, E.; Shu, Q.; Zhou, W.; Li, Z.; Wang, Z. Biodiesel production from algae cultivated in winter with artificial wastewater through $\mathrm{pH}$ regulation by acetic acid. Appl. Energy 2014, 128, 103-110. [CrossRef]

19. Sugashini, S.; Begum, K.M.M.S. Column Adsorption Studies for the Removal of Cr(VI) Ions by Ethylamine Modified Chitosan Carbonized Rice Husk Composite Beads with Modelling and Optimization. J. Chem. 2013, 2013, 1-11. [CrossRef]

20. Yaneva, Z.; Koumanova, B.; Allen, S. Applicability Comparison of Different kinetic/diffusion Models for 4-Nitrophenol Sorption on Rhizopus Oryzae Dead Biomass. Bulg. Chem. Commun. 2013, 45, 161-168.

21. Mor, S.; Chhoden, K.; Ravindra, K.; Khaiwal, R. Application of agro-waste rice husk ash for the removal of phosphate from the wastewater. J. Clean. Prod. 2016, 129, 673-680. [CrossRef]

22. Albadarin, A.B.; Mangwandi, C.; Al-Muhtaseb, A.; Walker, G.M.; Allen, S.J.; Ahmad, M. Kinetic and thermodynamics of chromium ions adsorption onto low-cost dolomite adsorbent. Chem. Eng. J. 2012, 179, 193-202. [CrossRef]

23. Tian, S.; Jiang, P.; Ning, P.; Su, Y. Enhanced adsorption removal of phosphate from water by mixed lanthanum/aluminum pillared montmorillonite. Chem. Eng. J. 2009, 151, 141-148. [CrossRef]

24. Ifelebuegu, A.; Salauh, H.T.; Zhang, Y.; Lynch, D.E. Adsorptive Properties of Poly(1-methylpyrrol2-ylsquaraine) Particles for the Removal of Endocrine-Disrupting Chemicals from Aqueous Solutions: Batch and Fixed-Bed Column Studies. Processes 2018, 6, 155. [CrossRef]

25. Mall, I.D.; Upadhyay, S.N.; Sharma, Y.C. A review on economical treatment of wastewaters and effluents by adsorption. Int. J. Environ. Stud. 1996, 51,77-124. [CrossRef]

26. Köse, T.E.; Kıvanç, B. Adsorption of phosphate from aqueous solutions using calcined waste eggshell. Chem. Eng. J. 2011, 178, 34-39. [CrossRef]

27. Zhou, J.; Yang, S.; Yu, J.; Shu, Z. Novel hollow microspheres of hierarchical zinc-aluminum layered double hydroxides and their enhanced adsorption capacity for phosphate in water. J. Hazard. Mater. 2011, 192, 1114-1121. [CrossRef]

28. Yuan, X.; Xia, W.; An, J.; Yin, J.; Zhou, X.; Yang, W. Kinetic and Thermodynamic Studies on the Phosphate Adsorption Removal by Dolomite Mineral. J. Chem. 2015, 2015, 1-8. [CrossRef]

29. Mezenner, N.Y.; Bensmaili, A. Kinetics and thermodynamic study of phosphate adsorption on iron hydroxide-eggshell waste. Chem. Eng. J. 2009, 147, 87-96. [CrossRef]

30. Qiu, H.; Lv, L.; Pan, B.; Zhang, Q.-J.; Zhang, W.-M.; Zhang, Q.-X. Critical review in adsorption kinetic models. J. Zhejiang Univ. A 2009, 10, 716-724. [CrossRef]

31. Yakout, S.; Elsherif, E. Batch Kinetics, Isotherm and Thermodynamic Studies of Adsorption of Strontium from Aqueous Solutions onto Low Cost Rice-Straw Based Carbons. Carbon Sci. Technol. 2010, 1, 144-153.

32. Subha, R.; Namasivayam, C. Modeling of Adsorption Isotherms and Kinetics of 2, 4, 6-Trichlorophenol Onto Microporous $\mathrm{ZnCl}_{2}$ Activated Coir Pith Carbon. J. Environ. Eng. Manag. 2008, 18, 275-280.

33. Ho, Y.S.; McKay, G. Pseudo-second order model for sorption processes. Process Biochem. 1999, 34, 451-465. [CrossRef]

34. Balouch, A.; Kolachi, M.; Talpur, F.N.; Khan, H.; Bhanger, M.I. Sorption Kinetics, Isotherm and Thermodynamic Modeling of Defluoridation of Ground Water Using Natural Adsorbents. Am. J. Anal. Chem. 2013, 4, 221-228. [CrossRef]

35. Dada, A.; Olalekan, A.; Olatunya, A.; Dada, O. Langmuir, Freundlich, Temkin and Dubinin-Radushkevich Isotherms Studies of Equilibrium Sorption of $\mathrm{Zn}^{2+}$ Unto Phosphoric Acid Modified Rice Husk. J. Appl. Chem. $2012,3,38-45$. 
36. Foo, K.Y.; Hameed, B. Insights into the modeling of adsorption isotherm systems. Chem. Eng. J. 2010, 156, 2-10. [CrossRef]

37. Boujelben, N.; Bouhamed, F.; Elouear, Z.; Bouzid, J.; Feki, M. Removal of phosphorus ions from aqueous solutions using manganese-oxide-coated sand and brick. Desalin. Water Treat. 2013, 52, 2282-2292. [CrossRef]

38. Hutson, N.D.; Yang, R.T. Theoretical basis for the Dubinin-Radushkevitch (D-R) adsorption isotherm equation. Adsorption 1997, 3, 189-195. [CrossRef]

39. Tempkin, M.; Pyzhev, V. Heavy Metals Removal and Isotherms Study. Acta Physiochim. URSS. 1940, 12, 217-222.

40. Dabrowski, A. Adsorption-From theory to practice. Adv. Colloid Interface Sci. 2001, 93, 135-224. [CrossRef]

41. Al-Anber, M.A. Thermodynamics Approach in the Adsorption of Heavy Metals; Intech Open Access Publisher: London, UK, 2011.

42. Huang, W.; Chen, J.; He, F.; Tang, J.; Li, D.; Zhu, Y.; Zhang, Y. Effective phosphate adsorption by Zr/Al-pillared montmorillonite: Insight into equilibrium, kinetics and thermodynamics. Appl. Clay Sci. 2015, 104, 252-260. [CrossRef]

43. Ifelebuegu, A.O. Removal of Steriod Hormones by Activated Carbon adsorption-Kinetic and Thermodynamic Studies. J. Environ. Prot. 2012, 3, 469-475. [CrossRef]

44. Ifelebuegu, A.O.; Ukpebor, J.E.; Obidiegwu, C.C.; Kwofi, B.C. Comparative potential of black tea leaves waste to granular activated carbon in adsorption of endocrine disrupting compounds from aqueous solution. Glob. J. Environ. Sci. Manag. 2015, 1, 205-214.

(C) 2020 by the authors. Licensee MDPI, Basel, Switzerland. This article is an open access article distributed under the terms and conditions of the Creative Commons Attribution (CC BY) license (http://creativecommons.org/licenses/by/4.0/). 